\title{
KEANEKARAGAMAN DAN PENYEBARAN Selaginella spp. DI INDONESIA DARI TAHUN 1998-2014
}

\author{
Andik Wijayanto \\ Jurusan Biologi, Fakultas Sains dan Teknologi, \\ UIN Maulana Malik Ibrahim Malang \\ wijayantoand@gmail.com
}

\begin{abstract}
Selaginella is a single genus of ferns allies belong to Selaginelaceae family that lives in moist areas and it is often found in highlands which spread approximately 700 species all over the world. Some Selaginella species have wide distribution and tend to be invasive, but the others are endemics or endangered. The diversity study and distribution of Selaginella in Indonesia fom 1998 until 2014 was done by exploring Selaginella articles from many source. In Indonesia from 1998 until 2014, there were found about 39 species of Selaginella, namely S. alligans, S. alutacia, S. angustiramea, S. apoensis, S. aristata, S. biformis, S. caudata, S. ciliaris, S. cupressina, S. delicatula, S. doederleinii, S. frondosa, $S$. illanosii, S. intermedia, S. involvens, S. ketra-ayam, S. kraussiana, S. longiaristata, S. magnifica, S. mayeri, S. modica, S. nummularia, S. opaca, S. ornata, S. padangensis, S. plana, S. remotifolia, S. repanda, S. rothertii, S. rupestris, S. singalanensis, S. spinulosa, $S$. subalpina, S. uncinata, S. velutina, S. vonroemeri, S. wallichii, S. willdenovii, and S. zollingeriana that spread in the islands of Sumatera, Bangka-Belitung, Java, Bali, Kalimantan, Sulawesi, Lombok, Maluku, and Irian Jaya with different altitude and patterns of spread.

Key words: Selaginella, keanekaragaman, penyebaran, Indonesia, 1998, 2014
\end{abstract}

\section{PENDAHULUAN}

Indonesia merupakan salah satu wilayah geografis yang memiliki keanekaragaman hayati yang sangat tinggi. Namun pengelolaan, pemanfaatan, maupun pengkajian berbagai kekayaan hayati ini belum optimal, khususnya hasil hutan bukan kayu atau Non Timber Forest Product (NTFPs).

Kurangnya pengkajian tentang NTFPs dan cara pandang bahwa hutan hanya sebagai sumber kayu bahan bangunan saja, karena hasil kayu memberikan devisa yang cukup besar bagi pemerintah (Purwanto 2007), merupakan beberapa penyebab terjadinya eksploitasi penebangan pohon di hutan yang tidak memperdulikan kelestarian yang berkelanjutan sehingga menyebabkan kerusakan ekosistem. Jika hal ini terus dibiarkan, dapat mengakibatkan hilangnya plasma nutfah.

Menurut Purwanto (2007) dan Ahmed dan Latif (2004), peran NTFPs berkisar 10-
80\% dari keseluruhan kebutuhan masyarakat di sekitar hutan, sehingga perlu dilakukan penelitian lebih mendalam tentang potensi pemanfaatan NTFPs. Salah satu NTFPs di Indonesia yang memiliki keanekaragaman yang tinggi adalah Selaginella.

Di Indonesia, Selaginella mempunyai nama lokal yang beragam antara lain tapak dara, cakar ayam, cemara kipas gunung, rumput solo (suku Jawa), paku rane biru (suku Sunda), menter (Jakarta), tai lantuan (Madura), rutu rutu (Maluku) (Winter \& Amoroso 2003; Setyawan \& Darusman 2008), dan rorak (Minahasa) (Zumsteg \& Weckerle 2007). Selain itu, Selaginella juga dikenal dengan nama shi shang bai, juan bai, chuan pai, huan hun ts'ao (Cina), sondotnulogo (Malaysia), pakongcipres, pakaunkung, pakong-tulog (Filipina), dok hin (Thailand), mong lung rong, cay chan vit, thach bachi (Vietnam) (Winter \& Amoroso 2003; Thomas 2002; Thomson 2007). 


\section{Klasifikasi Selaginella}

Selaginella Pal. Beauv. (Selaginellaceae Reichb.) termasuk divisi Lycopodiophyta, kelas Selaginellopsida, ordo Selaginalles. Kata Selaginella pertama kali diperkenalkan oleh seorang botanis Palisot de Beauvois (1805) dan mengklasifikasikan Selaginellaceae menjadi satu genus (The Global Biodiversity Information Facility 2015a) dan memasukkan sebagian besar spesies di subgenus Stachygynandrum (The Plant Encyclopedia 2015). Namun menurut Setyawan (2011), Palisot de Beauvois (1805) mengklasifikasikan Selaginellaceae menjadi empat genus dan Spring (1850) menyatukan menjadi satu genus yaitu Selaginella. Pada tahun 1854, Wilkomm membagi Selaginellaceae menjadi 3 genus dan berhasil mengidentifikasi 54 spesies (The Global Biodiversity Information Facility 2015b). Selain itu, studi tentang klasifikasi Selaginellaceae telah dilakukan oleh Spring (1850), Braun (1857), Baker (1883), Hieronymus (1901), Walton dan Alston (1938), Jermy (1986), Sojak (1992), dan Korall dan Kenrick (2001). Jermy (1986) mengklasifikasikan genus Selaginella menjadi lima subgenus yaitu Selaginella Pal. Beauv. (2 spesies), Ericetorum Jermy (3 spesies), Tetragonostachys Jermy ( $\sim 50$ spesies $)$, Stachygynandrum Baker ( $\sim 600$ spesies), dan Heterostachys Baker ( 60 spesies).

\section{Morfologi dan Habitus Selaginella}

Selaginella mempunyai akar yang panjang,

pendek, atau rizofor. Batang kecil, tegak, atau menjalar dengan akar di setiap intervalnya. Percabangan menggarpu. Daun tersusun spiral atau berhadapan, sepasang daun kecil menyerupai sisik di bagian lateral dan median batang yang sebagian besar dengan ukuran yang berbeda. Daun median lebih kecil dan berbeda bentuk dengan daun lateral. Strobili terdapat di ujung percabangan. Spora dua tipe yaitu mikrospora dan megaspora. Selaginella tumbuh di berbagai iklim dan tipe tanah dengan keanekaragaman tertinggi di hutan hujan tropis (Tjitrosoepomo 1994, XianChun 2001; Jinn-Lai \& Wang-Cheung 2003; Setyawan \& Darusman 2008). Contoh morfologi Selaginella terdapat pada gambar 1.

Selaginella termasuk tumbuhan herba perennial. Secara umum spesies Selaginella ditemukan pada daerah dengan kelembaban yang cukup, cahaya matahari dengan intensitas sedang dan ternaungi, tanah remah, pada tebing, tepi sungai, maupun area dengan permukaan yang datar (Wijayanto 2009).

Di sekitar tempat tumbuh Selaginella sering ditemukan tumbuhan harendong (Melastoma affine), Nephrolepis, rumput gajah (Pennisetum pupureum), rumput gewor (Commelina), cocor bebek (Kalanchoe), urang aring (Eclipta alba), alang-alang (Imperata), keji beling (Strobilanthes), Begonia, dan lumut hati seperti Marchantia (Wijayanto 2009).

Tumbuhan purba ini mampu bertahan dari seleksi alam tanpa modifikasi morfologi yang signifikan, dan kadangkadang disebut spike moss atau resurrection plants (Setyawan 2011).

\section{KEANEKARAGAMAN DAN PENYEBARAN}

Lebih dari 400 spesies Selaginella tersebar di dunia (Winter \& Amoroso 2003) bahkan dapat mencapai lebih dari 700 spesies (Jinn-Lai \& Wang-Cheung 2003). Eksplorasi keanekaragaman spesies ini di luar wilayah Indonesia dalam lingkup benua Asia antara lain di India (Panigrahi \& Dixit 1966), Taiwan (Jinn-Lai \& WangCheung 2003), Filipina (Tan 2013), Cina (Xian-Chun 2001), Malaysia, Burma, Thailand, Jepang, Papua Nugini, Australia, Amerika Serikat, Meksiko, dan beberapa negara di Afrika (Tagawa \& Iwatsuki 1967; Iwatsuki 1973; United States Department of Agriculture 2002; Winter \& Amoroso 2003).

Di Indonesia, pada tahun 1935, telah teridentifikasi sebanyak 23 spesies (Alston 1935), antara lain S. intermedia, S. ornata, 
S. willdenovii, S. plana, S. caudata, dan $S$. remotifolia (Tjitrosoepomo 1994). Dan pada tahun 2015 telah teridentifikasi sebanyak 39 spesies yaitu $S$. alligans, $S$. alutacia, S. angustiramea, S. apoensis, $S$. aristata, S. biformis, S. caudata, S. ciliaris, S. cupressina, S. delicatula, S. doederleinii, $S$. frondosa, S. illanosii, S. intermedia, $S$. involvens, S. ketra-ayam, S. kraussiana, S. longiaristata, S. magnifica, S. mayeri, S. modica, S. nummularia, S. opaca, S. ornata, $S$. padangensis, S. plana, S. remotifolia, $S$. repanda, $S$. rothertii, $S$. rupestris, $S$. singalanensis, S. spinulosa, S. subalpina, $S$. uncinata, $S$. velutina, $S$. vonroemeri, $S$. wallichii, $S$. willdenovii, dan $S$. zollingeriana dengan ketinggian dan pola penyebaran yang berbeda (Tabel 1). Spesies dengan persebaran terluas adalah spesies $S$. plana, S. remotifolia, dan $S$. cupressina yang masing-masing tersebar di 4 pulau yang berbeda.

Masing-masing spesies Selaginella mempunyai karakter khas yang dapat digunakan untuk membedakan antara spesies yang satu dengan yang lainnya.
Selaginella willdenovii mirip dengan $S$. involvens yaitu mempunyai pola pertumbuhan batang memanjat dan rizoma yang panjang merayap. Namun $S$. willdenovii mempunyai daun iridesen berwarna hijau kuning kebiruan sedangkan $S$. involvens hanya mempunyai satu warna pada daun dengan warna hijau atau merah kecoklatan mengkilap dan pola percabangan yang lebih meruncing ke ujung dibandingkan $S$. willdenovii (Wijayanto 2009)

Selaginella ornata dan $S$. plana mempunyai tipe pertumbuhan batang yang sama, yaitu tegak. Namun kedua spesies ini mudah dibedakan karena $S$. ornata mempunyai rizofor dan batang bagian bawah berwarna merah kecoklatan dan mudah patah, sedangkan $S$. plana mempunyai bentuk percabangan seperti bulat telur dan daun lateral yang rapat (Wijayanto 2009).

Selaginella alutacia dan $S$. ciliaris sangat mudah dikenali dari ukurannya yang sangat kecil, yaitu 3-5 cm dan tumbuh pada habitat yang kering. 


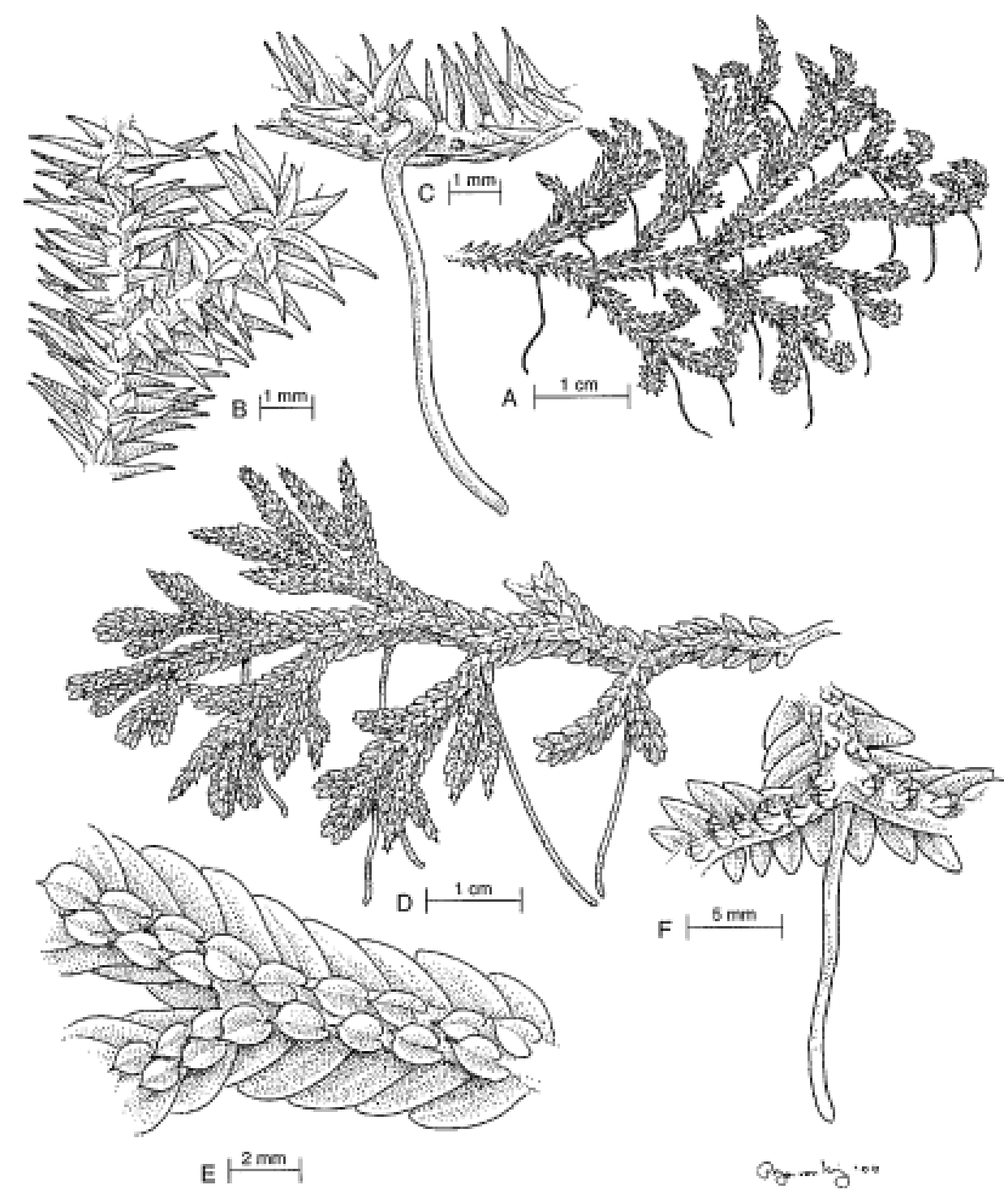

Gambar 1. Morfologi Selaginella. A-C Selaginella arizonica (subg. Tetragonostachys). D-F Selaginella martensii (subg. Stachygynandrum). Ilustrator Pollyanna von Knorring (Korall dan Kenrick 2002)

Masing-masing spesies mempunyai pola percabangan yang berbeda-beda. Misalnya $S$. willdenovii mempunyai pola percabangan dikotom berbentuk bulat telur teratur. $S$. ornata mempunyai pola percabangan dikotom berbentuk sudip. S. plana mempunyai pola percabangan dikotom berbentuk bulat telur

teratur. S. involvens mempunyai pola percabangan dikotom berbentuk lanset. $S$. alutacia mempunyai pola percabangan dikotom berbentuk bulat telur acak. $S$. intermedia mempunyai pola percabangan dikotom berbentuk bulat telur dan rapat. $S$. subalpina mempunyai pola percabangan dikotom yang mengumpul di ujung percabangan membentuk setengah lingkaran seperti ginjal dan renggang (Wijayanto 2009).

Selaginella intermedia mempunyai pola percabangan yang mirip dengan $S$. subalpina yaitu membentuk setengah lingkaran. Namun $S$. intermedia mempunyai pola percabangan yang teratur dan rapat sedangkan $S$. subalpina mempunyai pola percabangan mengumpul di ujung percabangan primer dan renggang. Selain itu, kedua spesies ini mempunyai perbedaan pada perbandingan antara panjang arista dengan 
Tabel 1 Keanekaragaman dan penyebaran Selaginella di Indonesia dari tahun 1998-2014

\begin{tabular}{|c|c|c|c|c|c|c|}
\hline $\begin{array}{c}\mathrm{N} \\
\mathrm{O}\end{array}$ & Nama Spesies & Lokasi & Provinsi & $\begin{array}{c}\text { Pulau/ } \\
\text { Kepulauan }\end{array}$ & $\begin{array}{l}\text { Ketingg } \\
\text { ian } \\
\text { (mdpl) }\end{array}$ & Pustaka \\
\hline 1 & S. intermedia & $\begin{array}{l}\text { Taman Nasional Gunung Halimun } \\
\text { Salak }\end{array}$ & Jawa Barat & Jawa & $0-1150$ & $\begin{array}{l}\text { Wijayanto 2009, Setyawan 2009, } \\
\text { Setyawan } 2012\end{array}$ \\
\hline 2 & S. ornata & $\begin{array}{l}\text { Taman Nasional Gunung Halimun } \\
\text { Salak, Gunung Lawu, -, Curug } \\
\text { Cikaracak Bogor }\end{array}$ & $\begin{array}{l}\text { Jawa Barat, Jawa } \\
\text { Timur, Jawa Tengah }\end{array}$ & Jawa & $0-1400$ & $\begin{array}{l}\text { Wijayanto 2009, Setyawan \& } \\
\text { Sugiyarto 2001, Setyawan } 2009 \text {, } \\
\text { Panjaitan 2013, Jamsuri } 2007\end{array}$ \\
\hline 3 & S. plana & $\begin{array}{l}\text { Taman Nasional Gunung Halimun } \\
\text { Salak, Gunung Rinjani, Suku } \\
\text { Dayak Meratus, -, Taman } \\
\text { Nasional Atakejawe-Lolobata, } \\
\text { Taman Wisata Situ Lembang }\end{array}$ & $\begin{array}{l}\text { Jawa Barat, Nusa } \\
\text { Tenggara Barat, } \\
\text { Kalimantan Selatan, } \\
\text { Jawa Tengah, } \\
\text { Maluku Utara } \\
\end{array}$ & $\begin{array}{l}\text { Jawa, Lombok, } \\
\text { Kalimantan, } \\
\text { Maluku }\end{array}$ & $0-1400$ & $\begin{array}{l}\text { Wijayanto 2009, Setyawan 2009, } \\
\text { Noorcahyati \& Arifin 2014, } \\
\text { Panjaitan 2013, Balai Taman } \\
\text { Nasional Atakejawe-Lolobata 2009, } \\
\text { Kusdianti et al 2008 }\end{array}$ \\
\hline 4 & S. willdenovii & $\begin{array}{l}\text { Taman Nasional Gunung Halimun } \\
\text { Salak }\end{array}$ & Jawa Barat & Jawa & $0-1100$ & $\begin{array}{l}\text { Wijayanto 2009, Winter and Jansen } \\
2003\end{array}$ \\
\hline 5 & S. involvens & $\begin{array}{l}\text { Taman Nasional Gunung Halimun } \\
\text { Salak, Gunung Lawu, - }\end{array}$ & $\begin{array}{l}\text { Jawa Barat, Jawa } \\
\text { Timur, Jawa Tengah }\end{array}$ & Jawa & $0-1400$ & $\begin{array}{l}\text { Wijayanto 2009, Setyawan 2009, } \\
\text { Setyawan et al. 2013, Panjaitan } \\
2013\end{array}$ \\
\hline 6 & S. alutacia & $\begin{array}{l}\text { Taman Nasional Gunung Halimun } \\
\text { Salak }\end{array}$ & Jawa Barat & Jawa & $0-900$ & Wijayanto 2009 \\
\hline 7 & S. subalpina & $\begin{array}{l}\text { Taman Nasional Gunung Halimun } \\
\text { Salak }\end{array}$ & $\begin{array}{l}\text { Jawa Barat, Jawa } \\
\text { Tengah }\end{array}$ & Jawa & $\begin{array}{l}900- \\
1100\end{array}$ & $\begin{array}{l}\text { Wijayanto 2009, Setyawan 2009, } \\
\text { Panjaitan } 2013\end{array}$ \\
\hline 8 & $\begin{array}{l}S . \\
\text { zollingeriana } \\
\end{array}$ & Gunung Lawu & Jawa Timur & Jawa & $\begin{array}{c}1100- \\
400\end{array}$ & Setyawan et al. 2013 \\
\hline 9 & S. opaca & $\begin{array}{l}\text { Gunung Lawu, Cagar Alam } \\
\text { Batukahu, - }\end{array}$ & $\begin{array}{l}\text { Jawa Timur, Bali, } \\
\text { Jawa Tengah }\end{array}$ & Jawa, Bali & $\begin{array}{l}950- \\
2150\end{array}$ & $\begin{array}{l}\text { Setyawan et al. 2013, Setyawan } \\
\text { 2009, Panjaitan 2013, Setyawan } \\
2012\end{array}$ \\
\hline 10 & S. remotifolia & $\begin{array}{l}\text { Gunung Lawu, Cagar Alam } \\
\text { Batukahu, - }\end{array}$ & $\begin{array}{l}\text { Jawa Timur, Bali, } \\
\text { Jawa Tengah }\end{array}$ & $\begin{array}{l}\text { Jawa, Bali, } \\
\text { Sumatera, Irian } \\
\text { Jaya }\end{array}$ & $\begin{array}{l}950- \\
2200\end{array}$ & $\begin{array}{l}\text { Setyawan et al. 2013, Setyawan } \\
\text { 2009, Panjaitan 2013, Setyawan } \\
\text { 2012, Tan BC } 2013\end{array}$ \\
\hline
\end{tabular}




\begin{tabular}{|c|c|c|c|c|c|c|}
\hline 11 & S. aristata & Gunung Lawu, - & $\begin{array}{l}\text { Jawa Timur, Jawa } \\
\text { Tengah }\end{array}$ & Jawa, Sulawesi & $\begin{array}{l}350- \\
1400\end{array}$ & $\begin{array}{l}\text { Setyawan } \text { et al. 2013, Panjaitan } \\
\text { 2013, Setyawan 2012, Tan } 2013\end{array}$ \\
\hline 12 & S. ciliaris & Gunung Lawu, - & $\begin{array}{l}\text { Jawa Timur, Jawa } \\
\text { Tengah }\end{array}$ & Jawa & $0-1400$ & $\begin{array}{l}\text { Setyawan et al. 2013, Panjaitan } \\
\text { 2013, Setyawan } 2012\end{array}$ \\
\hline 13 & $\begin{array}{l}\text { S. } \\
\text { singalanensis }\end{array}$ & Gunung Lawu & Jawa Timur & Jawa & $\begin{array}{c}1100- \\
400\end{array}$ & Setyawan et al. 2013 \\
\hline 14 & S. frondosa & - & - & Jawa & - & Setyawan 2009 \\
\hline 15 & $\begin{array}{l}\text { S. } \\
\text { longiaristata }\end{array}$ & - & - & Jawa & - & Setyawan 2009, Tan BC 2013 \\
\hline 16 & S. repanda & - & - & Jawa & $150-200$ & Setyawan 2009, Setyawan 2012 \\
\hline 17 & S. rothertii & - & - & Jawa & - & Setyawan 2009 \\
\hline 18 & $\begin{array}{l}S . \\
\text { angustiramea }\end{array}$ & $\begin{array}{l}\text { Cagar Alam Pegunungan Cyclops, } \\
\text { Taman Nasional Atakejawe- } \\
\text { Lolobata }\end{array}$ & $\begin{array}{l}\text { Papua, Maluku } \\
\text { Utara }\end{array}$ & Irian Jaya, Maluku & - & Setyawan 2009 \\
\hline 19 & S. caudata & $\begin{array}{l}\text { Cagar Alam Pegunungan Cyclops, } \\
\text { Hutan Lindung Gunung Meja, } \\
\text { Suaka Margasatwa Nantu }\end{array}$ & $\begin{array}{l}\text { Papua, Papua Barat, } \\
\text { Gorontalo }\end{array}$ & $\begin{array}{l}\text { Irian Jaya, } \\
\text { Sulawesi }\end{array}$ & - & Setyawan 2009 \\
\hline 20 & S. velutina & $\begin{array}{l}\text { Cagar Alam Pegunungan Cyclops, } \\
\text { Taman Nasional Atakejawe- } \\
\text { Lolobata }\end{array}$ & $\begin{array}{l}\text { Papua, Maluku } \\
\text { Utara }\end{array}$ & Irian Jaya, Maluku & - & Setyawan 2009 \\
\hline 21 & S. cupressina & $\begin{array}{l}\text { Gunung Gamalama, Gunung } \\
\text { Soputan, Suaka Margasatwa } \\
\text { Nantu, -, - }\end{array}$ & $\begin{array}{l}\text { Maluku Utara, } \\
\text { Sulawesi Utara, } \\
\text { Gorontalo, -, - } \\
\end{array}$ & $\begin{array}{l}\text { Maluku, Sulawesi, } \\
\text { Jawa, Kalimantan }\end{array}$ & - & Setyawan 2009, Tan BC 2013 \\
\hline 22 & S. vonroemeri & Suaka Margasatwa Nantu & Gorontalo & Sulawesi & - & Setyawan 2009 \\
\hline 23 & S. ketra-ayam & Gunung Menumbing & Bangka Belitung & Bangka Belitung & - & Setyawan 2009 \\
\hline 24 & S. mayeri & Taman Nasional Gunung Leuser & Aceh & Sumatera & - & \\
\hline 25 & S. magnifica & Suku Dayak Meratus & Kalimantan Selatan & Kalimantan & - & Caniago \& Siebert 1998 \\
\hline 26 & $\begin{array}{l}\text { S. } \\
\text { padangensis }\end{array}$ & - & - & $\begin{array}{l}\text { Sumatera, } \\
\text { Kalimantan }\end{array}$ & - & Winter and Jansen 2003 \\
\hline 27 & S. rupestris & - & - & Sumatera & - & Winter and Jansen 2003 \\
\hline 28 & S. wallichii & - & - & Sumatera & - & Winter and Jansen 2003 \\
\hline 29 & S. modica & - & Jawa Tengah & Jawa & - & Panjaitan 2013 \\
\hline
\end{tabular}




\begin{tabular}{|c|c|c|c|c|c|c|}
\hline 30 & S. uncinata & -, Kebun Raya Cibodas, Bandung & $\begin{array}{l}\text { Jawa Tengah, Jawa } \\
\text { Barat }\end{array}$ & Jawa & 700 & $\begin{array}{l}\text { Setyawan 2012, Setyawan 2014, } \\
\text { Harli } 2013\end{array}$ \\
\hline 31 & S. doederleinii & Cagar Alam Batukahu & Bali & Bali & 1500 & Sutomo dan Fardila 2013 \\
\hline 32 & S. alligans & - & - & Sulawesi & - & Tan BC 2013 \\
\hline 33 & S. apoensis & - & - & Sulawesi & & Tan BC 2013 \\
\hline 34 & S. biformis & - & - & - & - & Tan BC 2013 \\
\hline 35 & S. delicatula & - & - & $\begin{array}{l}\text { Kalimantan, } \\
\text { Sulawesi }\end{array}$ & - & Tan BC 2013 \\
\hline 36 & S. illanosii & - & - & Kalimantan & - & Tan BC 2013 \\
\hline 37 & $\begin{array}{l}\text { S. } \\
\text { nummularia }\end{array}$ & & & Sulawesi & & Tan BC 2013 \\
\hline 38 & S. kraussiana & Malang & Jawa Timur & Jawa & - & Sunarmi dan Sarwono 2004 \\
\hline 39 & S. spinulosa & Malang & Jawa Timur & Jawa & - & Sunarmi dan Sarwono 2004 \\
\hline
\end{tabular}


panjang daun median. $S$. intermedia mempunyai panjang arista setengah dari panjang daun median sedangkan $S$. subalpina mempunyai panjang arista kurang dari setengah panjang daun median (Wijayanto 2009) (Gambar 2).

Penelitian sebelumnya, Selaginella dijumpai di Sumatera, Jawa, Kalimantan, dan Maluku (Tagawa \& Iwatsuki 1967; Iwatsuki 1973; Winter \& Amoroso 2003) dengan kelimpahan yang berbeda antara lain Kalimantan (58 spesies), Papua Nugini (55 spesies), Sumatera (29 spesies), Sulawesi (21 spesies), Maluku (18 spesies), dan Sunda Kecil (9 spesies) (Camus 1997).

Pada tahun 1998-2014, dijumpai Selaginella di pulau Sumatera, BangkaBelitung, Jawa, Bali, Kalimantan, Sulawesi, Lombok, Maluku, dan Irian Jaya. Dengan penelitian terbanyak di pulau Jawa, khususnya Jawa Barat dan Jawa Tengah (Gambar 3).

Di pulau Sumatera dijumpai 5 spesies Selaginella, yaitu $S$. remotifolia, $S$. mayeri, $S$. padangensis, $S$. ruprestris, dan $S$. wallichii. Di pulau Bangka-Belitung
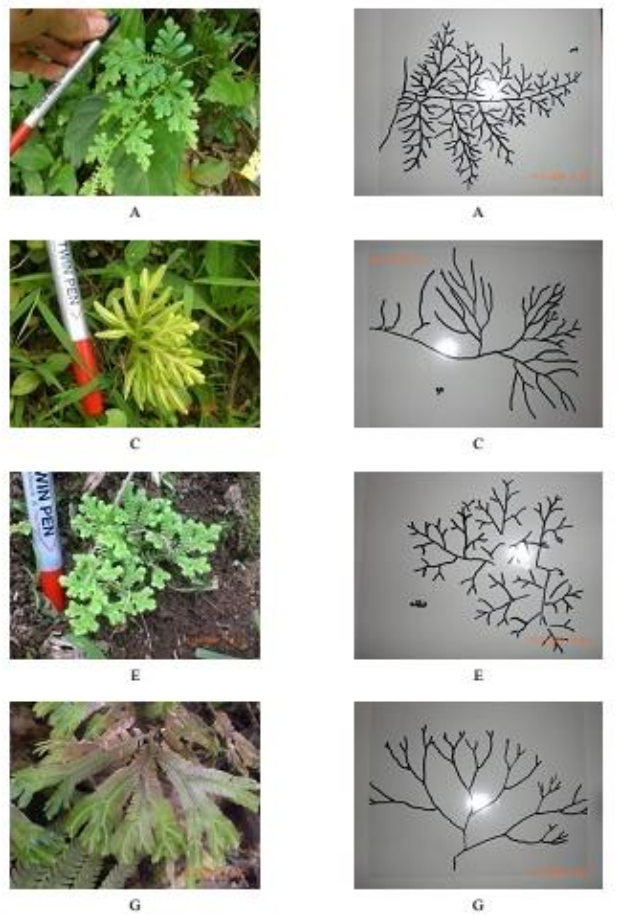

Gambar 2 Beberapa spesies Selaginella yang ditemukan di Indonesia dan pola percabangannya (A) S. willdenovii, (B) S. ornata, (C) S. plana, (D) S. involvens, (E) S. alutacia, (F) S. intermedia, (G) S.subalpina (Wijayanto 2009) 


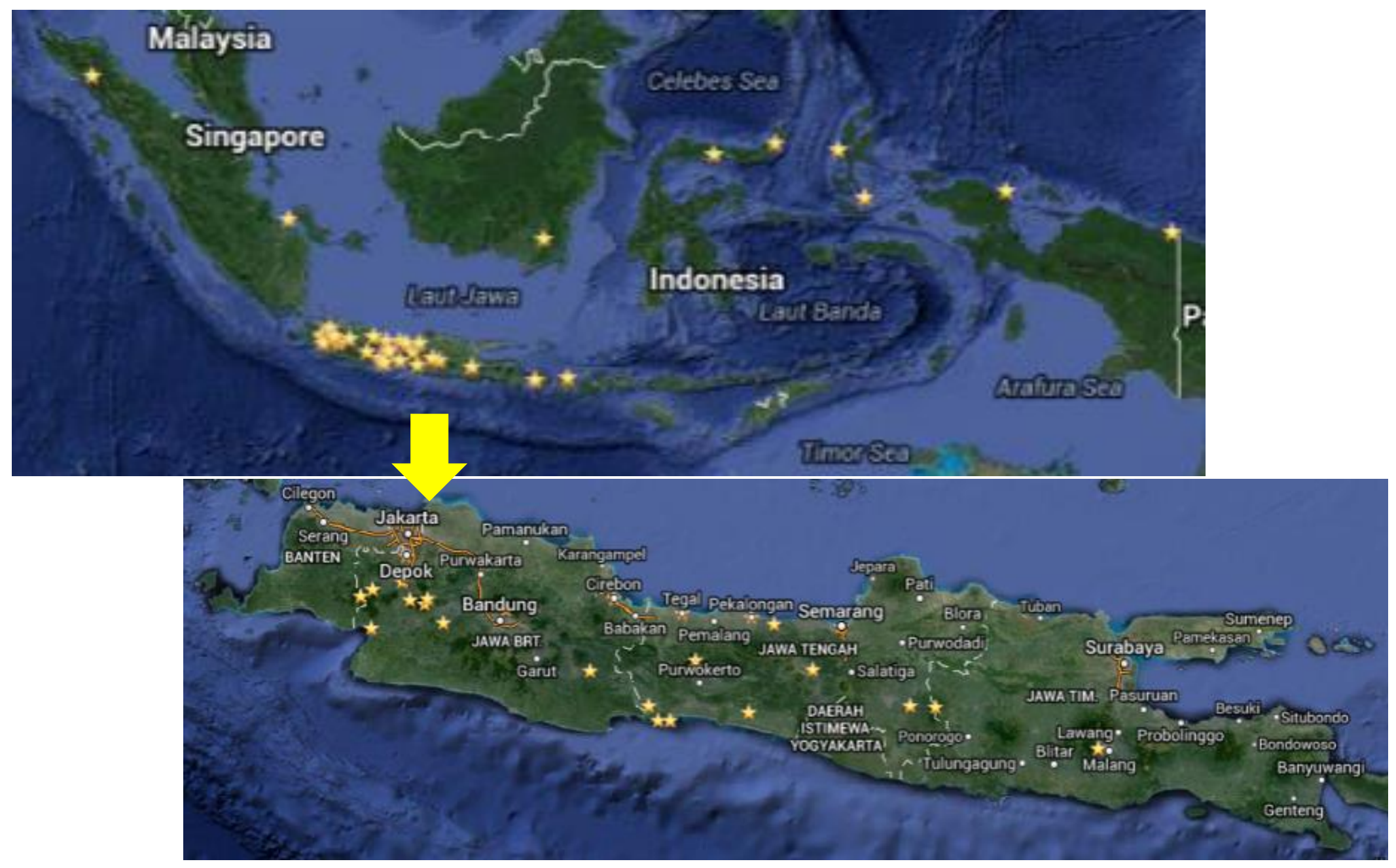

Gambar 3 Penyebaran Selaginella di Indonesia dari tahun 1998-2014. Gambar menggunakan Google Map 2015.

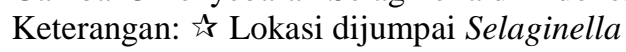




\section{SIMPULAN}

Terdapat 40 spesies Selaginella yang teridentifikasi di Indonesia mulai tahun 19982014 yaitu S. alligans, S. alutacia, S. angustiramea, $S$. apoensis, $S$. aristata, $S$. biformis, S. caudata, S. ciliaris, S. cupressina, S. delicatula, S. doederleinii, S. frondosa, S. illanosii, S. intermedia, S. involvens, S. ketraayam, $S$. kraussiana, $S$. longiaristata, $S$. magnifica, $S$. mayeri, $S$. modica, $S$. nummularia, $S$. opaca, $S$. ornata, $S$. padangensis, $S$. plana, $S$. remotifolia, $S$. repanda, $S$. rothertii, $S$. rupestris, $S$. singalanensis, S. spinulosa, S. subalpina, $S$. uncinata, $S$. velutina, $S$. vonroemeri, $S$. wallichii, S. willdenovii, dan S. zollingeriana yang tersebar di pulau Sumatera, BangkaBelitung, Jawa, Bali, Kalimantan, Sulawesi, Lombok, Maluku, dan Irian Jaya dengan ketinggian dan pola penyebaran yang berbeda.

Spesies dengan persebaran terluas adalah spesies S. plana, $S$. remotifolia, dan $S$. cupressina yang masing-masing tersebar di 4 pulau yang berbeda. Kelimpahan spesies Selaginella tertinggi terdapat di pulau Jawa dengan dijumpai 22 spesies.

\section{DAFTAR PUSTAKA}

Ahmed A dan Latif A. 2004. Non-Timber Forest Products: A Substitute for Livelihood of the Marginal Community in Kalash Valley, Northern Pakistan. [Terhubung berkala].

http://www.siu.edu/ ebl/leaflest/ajaz .htm [27 Des 2007]

Alston AHG. 1935. The Selaginella of the Malay Island:1 Java and the Lesser Sunda Island. Bul Jard Bot Buitenzorg Serie 3,13: 423-442.

Baker JG. 1883. A synopsis of the genus Selaginella. J of Botany 21: $1-5,42$ 46, 80-84, 97-100, 141-145, 210 213, 240-244.

[Balai Taman Nasional Atakejawe-Lolobata]. 2009. Buku Statistik 2009. Balai Taman Nasional Atakejawe-
Lolobata. Ternate: Balai Taman Nasional Atakejawe-Lolobata Press.

Braun A. 1857. Appendix plantarum novarum et minus cognitarum. In Horto regio botanico Berolinensi coluntur 12-22.

Camus JM. 1997. The genus Selaginella (Selaginellaceae) in Malesia. In Dransfield, J. (ed.). Plant Diversity of Malesia III:59-69.London: Royal Botanic Garden.

Caniago I, SF Siebert. 1998. Medicinal plant ecology, knowledge and conservation in Kalimantan, Indonesia. Econ Bot 52(3):229-250

Harli R. 2013. Keanekaragaman Selaginella di Jawa Barat. Skripsi. Bogor: IPB Press.

Hieronymus G. 1901. Selaginellaceae. In A. Engler and K. Prantl [eds.], Die Natu"rlichen Pflanzenfamilien, vol. 1(4):621-716. Germany: W. Engelmann Leipzig Press

Iwatsuki K. 1973. Pteridophytes of Northern Sumatra: a report of botanical trip in 1971. Southeast Asian Studies 11(2):277-296.

Jamsuri. 2007. Autekologi Tumbuhan Obat Selaginella Doederleinii Hieron Di Sebagian Kawasan Hutan Bukit Pohen Cagar Alam Batukahu, Bedugul

Bali. Skripsi. Jakarta: UIN Syarif Hidayatullah Press.

Jermy AC. 1986. Subgeneric names in Selaginella. Fern Gazette 13:117118.

Jinn-Lai T dan Wang-Cheung S. 2003. Flora of Taiwan 2nd Vol 1. Taiwan: National Taiwan Univ Pr.

Korall P dan Kenrick P. 2002. Phylogenetic Relationships In Selaginellaceae Based On Rbcl Sequences. American J of Bot 89(3):506-517.

Kusdianti, Tina SN, Syahbuddin M. 2008. Inventarisasi Tumbuhan yang. Berpotensi sebagai Obat di Taman 
Wisata Situ Lembang Bandung. Setyawan AD dan Sugiyarto. 2001. Bandung: UPI Press

Noorcahyati dan Arifin Z. 2014. Etnobotani tumbuhan berkhasiat obat Etnis Dayak Meratus Laksado Kalimantan Selatan dan upaya konservasi di KHDTK Samboja. http://www.forda-of.org/index.php/ download/attach/1_Etnobotani_Tum buhan_Berkhasiat_Obat.pdf/3922.

Palisot de Beauvois, AMFJ (1805) Prodrome des cinquieme et sixieme familles de l'aetheogamie. Les mousses. Les lycopodes. Paris: Fournier Fils Press.

Panigrahi G dan Dixit RD. 1996. Studies in the systematics of Indian Selaginella I. J Indian Bot Soc 34(4): 191-209.

Panjaitan H. 2013. Keanekaragaman Selaginella di Jawa Tengah. Skripsi. Bogor: IPB Press.

Purwanto Y. 2007. Hasil hutan bukan kayu (NTFPs): terminologi dan perannya bagi masyarakat di sekitar hutan. Bogor: LIPI.

Setyawan AD. 2009. Traditionally utilization of Selaginella; field research and literature

review. J Nusantara Bioscience 1(3):146-158.

Setyawan AD. 2011. REVIEW: Senyawa Biflavonoid pada Selaginella Pal. Beauv. dan Pemanfaatannya. J Biodiv 12(2):112-124

Setyawan AD. 2012. Altitudinal distribution of Selaginella in the southern part or Central Java. Proc Soc Indon Biodiv Intl Conf 1: 153-157.

Setyawan AD. 2014. Short Communication: A new record of naturalized Selaginella uncinata (Desv.) Spring (Selaginellaceae) from Java, Indonesia. J Biodiv. 15(2):261-268

Setyawan AD dan Darusman LK. 2008. Review: Senyawa biflavonoid pada Selaginella Pal. Beauv. dan pemanfaatannya. J Biol Div Biodiv 9:64-81.

Keanekaragaman Flora Hutan Jobolarangan

Gunung Lawu: 1. Cryptogamae. J Biodiv 2(1):115-122.

Setyawan AD, Sutarno, Sugiyarto. 2003. Species diversity of Selaginella in Mount Lawu, Java, Indonesia. J Biodiv 14(1):1-9

Sojak J. 1992. Generische Problematik der Selaginellaceae. Preslia 64: 151-158.

Spring AF. 1850. Monographie de la famille des Lycopodiacees, 2nd partie. Mem Acad R Sci Lett Belg 24: 1-358

Sunarmi dan Sarwono. 2004. Inventarisasi tumbuhan paku di daerah Malang. Berk. Penel. Hayati: 10 (71-74), 2004.

http://www.berkalahayati.org/index. php/bph/article/download/552/440.

Sutomo dan Fardila D. 2013. Autekologi Tumbuhan Obat Selaginella Doederleinii Hieron Di Sebagian Kawasan Hutan Bukit Pohen Cagar Alam Batukahu, Bedugul Bali. J Penel Hut dan Konserv Alam 10(2):153-161.

Tagawa M dan Iwatsuki K. 1967. Enumeration of Thai pteridophytes collected during 1965-66. Tokyo: Tokyo Univ Pr.

Tan BC. 2013. The Selaginella flora, a good indicator of the Philippine pleistocene island groups. Philip J of Science 142: 211-213.

[The Global Biodiversity Information Facility]. 2015a. Selaginella Palisot de Beauvois 1804. [terhubung berkala]. http:// www.gbif.org/species/102462587 [13 Jan 2015]

[The Global Biodiversity Information Facility]. 2015b. Selaginellaceae Willkomm 1854. [terhubung berkala]. http://www.gbif.org /species/102234484. [13 Jan 2015]

[The Plant Encyclopedia]. 2015. Selaginella. [terhubung berkala]. http:// 
theplantencyclopedia.org/wiki/Selag inella [13 Jan 2015]

Thomas SCL. 2002. Chinese and Related North American Herbs: Phytopharmacology and Therapeutic Values. New York: CRC Pr.

Thomson GE. 2007. The Health Benefit of Traditional Chinese Plant Medicine: Weighing the scientific evidence. Australia: RIRDC Pr.

Tjitrosoepomo G. 1994. Taksonomi Tumbuhan. Jakarta: Bhratara Karya Aksara Pr.

[United States Department of Agriculture]. 2002. National Genetic Resources Program. Germplasm Resources Information Network - (GRIN) National Germplasm Resources Laboratory, Beltsville, Maryland. [terhubung berkala]. http://www.arsgrin.gov/cgi-bin/npgs/html/ taxon.pl?33581 (11 April 2008)

Walton J dan Alston AHG. 1938. Lycopodiinae. In F. Verdoorn [ed.] Manual of pteridology, 500-506. Martinus Nijhoff, The Hague, The Netherlands.

Wijayanto A. 2009. Biodiversitas, Etnobotani, dan Kemampuan Antioksidan Selaginella spp. Asal Taman Nasional Gunung Halimun Salak (TNGHS). Skripsi. Bogor: Institut Pertanian Bogor Press.

Winter WP de dan Amoroso VB, editor. 2003. Plant Resources of South-East Asia No 15(2). Cryptogams: Fern and Fern Allies. Bogor: Prosea Foundation Pr.

Winter WP de dan Jnasen PCM. 2003. Selaginella Pal. Beauv. In: de Winter

WP, Amoroso VB (eds). Plant resources of South-East Asia 15 (2) Cryptogams: ferns and fern allies. Backhuys. Leiden.

Xian-Chun Z. 2001. Studies on the Chinese species of Selaginellaceae (I): Selaginella subgenus
Tetragonostachys Jermy. J Acta Phytotax Sinica 39(4): 345-355.

Zumsteg IS dan Weckerle CS. 2007. Bakera, a herbal steam bath for postnatal care in Minahasa (Indonesia): documentation of the plants used and assessment of the method. $\mathbf{J}$ Ethnophar 111: 641-650. 